\title{
New members of the Editorial Board; TelSoc's first year; and Australia's hunger for networked data
}

\author{
Peter Gerrand \\ Managing Editor
}

- Summary: A welcome to this Journal's two new editors; congratulations to the Journal's publisher, TelSoc, on its first year of operation; and observations on the continuing hunger in Australia for networked data, of which Big Data (our major theme for this issue) will be an important future component.

\section{New members of the Editorial Board}

I am delighted to announce that Dr Marta Poblet and Dr Mark Gregory have agreed to join the multidisciplinary Editorial Board of this Journal; the other distinguished members are listed here. The most important role of members of of the Editorial Board is to help source timely, relevant and authoritative articles and themes for the Journal. The second important role lies in maintaining quality control of the Journal's contents through contributing to peer reviews, and in nominating other expert reviewers in their fields of expertise.

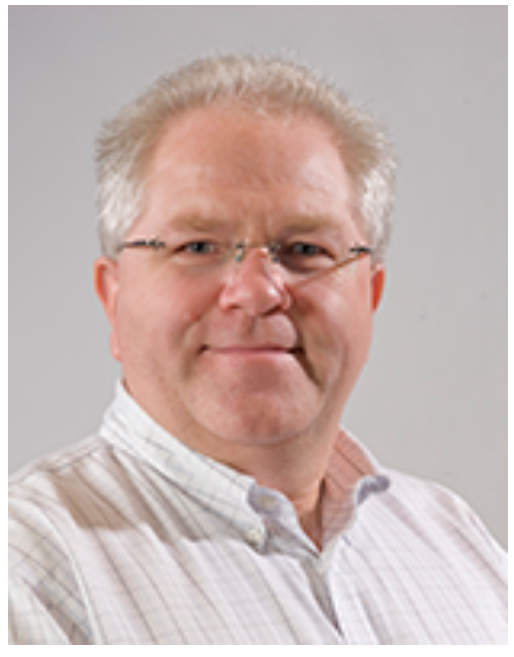

\section{Dr Mark Gregory}

Mark Gregory is a Senior Lecturer at RMIT University, where he has carried out research and teaching since 1992, after an earlier career as an Australian Army Officer. Mark has been a frequent contributor on telecommunications policy via columns in The Conversation (49 articles to date) and in Technology Spectator (over 50 articles to date), particularly on NBN policy, as well as having published more than 70 refereed papers on telecommunications engineering topics.

Mark has been active within Engineers Australia and he has been the lead organiser (General Chair) of the annual ATNAC conference in recent years. Mark was awarded an Australian Learning and Teaching Council Citation in 2009. And he has been a reviewer and author for this Journal. 


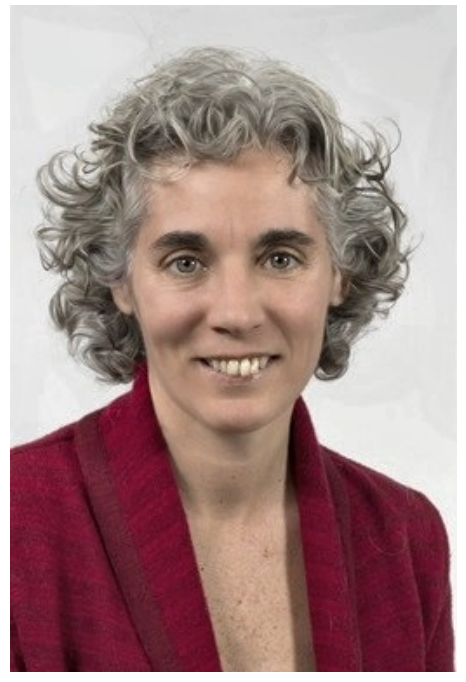

Dr Marta Poblet

Marta Poblet is an Associate Professor and Vice Chancellor's Senior Researcher at RMIT University. She is one of the co-founders of the Institute of Law and Technology at the Autonomous University of Barcelona and a past researcher at ICREA (Catalonia). She holds a Juris Doctorate and a Masters degree in International Legal Studies from Stanford University. Marta's research interests include law and conflict resolution, mobile technologies for development, and crowd sourced crisis mapping. She has published over 40 articles on these topics in international journals and books.

And yes, she is also a past author and reviewer for this Journal, and is the lead Guest Editor for our December issue, on the theme of telecommunications in disaster management.

\section{TelSoc's first year}

A rejuvenated TelSoc was established on 8 July 2013 to replace the Telecommunications Society of Australia (see the evolution of our 140-year history here), with the mission 'to promote knowledge, understanding and excellence in telecommunications and its applications including the digital economy'.

How has it fared so far? The following items from its Directors' Report 2013-14 illustrate the impressive range of activities organized by this grassroots society of enthusiastic volunteers:

- Over 25 local and national lecture events held in Melbourne, Sydney and Adelaide, where the great majority of our members are located. (We are always looking for volunteers to help convene lectures in the other capital cities.)

- The establishment of this new journal, the Australian Journal for Telecommunications and the Digital Economy, a peer reviewed, multidisciplinary journal with emphasis on contributions to communications policy, user experience, new technology and regulatory developments, and to the history of the industry. A total of 42 articles on important themes were published during TelSoc's first year. (This October 2014 issue adds 13 more.)

- The awarding of two Charles Todd Medals in 2013, to Michael Malone and Mike Quigley, the founding CEO's of iiNet and NBN Co respectively, for their outstanding contributions to telecommunications. 
- Holding the Charles Todd Oration in Sydney in October 2013, with Michael Malone as Orator; and the inaugural Henry Sutton Oration in Melbourne in May 2014, with veteran $\mathrm{ABC}$ science journalist Robin Williams as Orator.

- The establishment of a very fruitful collaboration with ITWire whereby TelSoc members receive free delivery of daily CommsWire daily newsletters and weekly summaries.

The Society's first Annual General Meeting takes place in Melbourne on 28 October, with five of the seven founding directors renominating, and three talented members of the industry putting themselves up for the new Board: Tristan Gutsche, Gary McLaren and Adam Redman.

To motivate attendance beyond the most stalwart of our supporters, Bob James and Gary McLaren will be providing what should be an entertaining as well as informative debate on 'The NBN Today - back on track, or could a new path emerge?'.

\section{Our hunger for networked data}

On 7 October the Australian Bureau of Statistics (ABS) announced that Australia had downloaded over one Exabyte (that's $10^{18}$ bytes) of data in the three months to June this year. It consisted of 996,160 terabytes via fixed broadband accesses, plus 38,734 terabytes via mobile devices. This result was remarkable for at least two reasons.

Firstly, the data downloaded by fixed-line broadband access accounted for $97 \%$ of all Internet downloads in those three months; mobile wireless accounted for less than $3 \%$, even though this had grown by a respectable $20 \%$ pa. The contrasts between these results justifies NBN Co's ongoing policy in rolling out fixed line access technologies rather than relying on cellular wireless to meet the great majority of user demand.

And it also shows the canniness of Telstra's plan to roll out 2 million WiFi hotspots nationally over the next five years. Each hotspot will be fed by fixed line broadband - free to Telstra customers, but at a charge to non-Telstra customers - thus reducing congestion on Telstra's cellular networks, and delivering high speed data to customers via the cheaper-perMB optical fibre networks that feed the hotspots.

Secondly the overall volume in April-June 2014 had increased by 51\% compared to the same period one year before. Correcting for a national population growth of $1.7 \%$ over this period slims this increase down a tiny bit to a per capita increase of $48 \%$ in average downloaded data. We're still experiencing huge annual growth. 
The historical data on broadband usage since 2008 (i.e. since the Global Financial Crisis) shows clear exponential growth, year on year. A $48 \%$ annual increase compounds to a gigantic 50 -fold increase over ten years. This suggests that those of us needing only a typical $12 \mathrm{Mbps}$ for peak download usage now will require typically $600 \mathrm{Mbps}$ for peak download usage in ten years' time, unless the pattern of data usage around the clock changes drastically.

\section{The additional impact of 'Big Data'}

Furthermore the much anticipated 'Internet of Things' is beginning to generate vast amounts of data which will impact on our national data networks in very challenging ways. The Square Kilometre Array radio telescope, the SIRCA Sense-T agricultural data trial in Tasmania, and emerging vehicle-to-vehicle communications are early examples. Big Data (the major theme of this edition of the Journal) is already here and growing fast. Connections to businesses and consumer premises will not be exempt.

Because of the likely impact of Big Data, the projections for data uploads and downloads during the decade of the NBN rollout will need to be lifted even higher.

\section{How well are our networks delivering on the capability to handle our exponentially growing data streams?}

The best news is that Australia's mobile network infrastructure is in good shape: the OECD's most recent comparative statistics show Australia as second only to Finland in the number of wireless broadband subscriptions at December 2013 (OECD 2014). One observes that the three major carriers (Telstra, Optus and Vodafone) are continuing to invest in new $4 \mathrm{G}$ infrastructure to maximize their cellular footprints. But as we have seen from the ABS figures (2014), the wireless networks only account for some $3 \%$ of the total downloaded data.

The news is not quite so good on fixed line capacity. Australia penetration per capita of fixed line broadband connections at December 2013 was only 26\%, placing us at 21st in the OECD list, compared to New Zealand $\left(15^{\text {th }}\right)$ with $30 \%$ and the world leader Switzerland's impressive $45 \%$ penetration. (The Netherlands and Denmark were placed $2^{\text {nd }}$ and $3^{\text {rd }}$ with c. $40 \%$ each.) We can be tempted to blame our 'tyranny of distance' as a handicap, but Canada, similarly challenged geographically, had reached $33.5 \%$ by last December.

And against the continuing evidence of exponentially growing data usage, Australia is falling further behind other countries in average broadband download speeds (at 15.53 average Mbps, we are now $57^{\text {th }}$ of 193 countries according to OOKLA on 13 October).

\section{The need to keep accelerating the rollout of the NBN's high speed connections must remain a high national priority.}




\section{References}

ABS (Australian Bureau of Statistics). 2014. 'Broadband internet downloads on the brink of one exabyte of data', 7 October 2014, at

http://www.abs.gov.au/ausstats/abs@.nsf/mediareleasesbyCatalogue/F2D32B785378B C9CCA25758Do02B6804?Opendocument

OECD. 2014. 'OECD Broadband Portal', updated 22 July 2014, at http://www.oecd.org/sti/broadband/oecdbroadbandportal.htm

Ookla. 2014. Ookla Net index Explorer, accessed 13 October 2014 at http://explorer.netindex.com/maps. 